\title{
Validation as the Integral Part of a Knowledge Management Process
}

\author{
Maria A. Mach and Mieczysław L. Owoc \\ University of Economics, Poland \\ mach@manager.ae.wroc.pi and mowoc@imanager.ae.wroc.pi
}

\begin{abstract}
Observing new concepts in information technology, we pay attention to its impact on more effective supporting human and organisational knowledge. Knowledge management (KM) is one of such promising and intriguing concepts. Its goals and infrastructures are defined in different ways, therefore interdisciplinary approach seems to be useful. We have presented a short survey of theoretical concepts in management, marketing and decision theory, which were adapted by the theory of KM. On the other hand, knowledge validation (KV), defined as two procedures: verification and evaluation any form of knowledge, is aimed on assuring its quality. The paper discusses the crucial interrelationships between knowledge validation and management. The main goal of this work is positioning KV activities in the context of knowledge management process, emphasising usability of $K V$ techniques during the whole process.
\end{abstract}

Keywords: managerial processes, knowledge management, knowledge validation \& verification, knowledge quality

\section{Introduction}

The role of knowledge in organisations has become obvious not long ago. Knowledge is nowadays treated as a critical resource of the firm, which leads to so-called knowledge-based view of the firm. As R. M. Grant points out, ,this approach identifies knowledge as the central resource of the firm, not only because of its quantitative importance to value added, but also because of its strategic importance" (Grant, 1999, p. 433).

Therefore the problem of knowledge management is crucial from the strategic point of view. At the same time, knowledge management is a very complex process because of its heterogeneity. Therefore there is a strong need to formalise knowledge management, which will help to identify and "catch" different aspects of the problem. What must be also pointed out here is the role of knowledge management as an innovative factor. Knowledge management can be seen as a process consisting of several tasks, more described later on. In order to obtain useful knowl-

Material published as part of this proceedings, either on-line or in print, is copyrighted by the author with permission granted to the publisher of Informing Science for this printing. Permission to make digital or paper copy of part or all of these works for personal or classroom use is granted without fee provided that the copies are not made or distributed for profit or commercial advantage AND that copies 1) bear this notice in full and 2) give the full citation on the first page. It is permissible to abstract these works so long as credit is given. To copy in all other cases or to republish or to post on a server or to redistribute to lists requires specific permission from the author. edge we have to perform certain specific and specialised procedures aimed at assuring knowledge quality. Such procedures can be termed as knowledge verification and its role seems to be very important in the whole management process.

The paper is organised as follows. We first present a short survey of theoretical concepts in management, marketing and decision theory, which were borrowed and adapted by the theory of knowledge management. Next we present a view of knowledge management as a process. This presentation is then followed by the presentation of the methods of knowledge verification in the KM context. Conclusions form the last part of the article.

\section{Theoretical and managerial back- ground for knowledge management and validation}

Clearly, knowledge management theory borrowed and adapted many concepts and solutions (theoretical and practical) from theory of organisation, management, and marketing. Therefore it seems to be purposeful to present here a short survey on those aspect of this theory, which had an impact on the knowledge management theory.

The roots of knowledge management theory can be seen in the fact, that the theory of organisations and management itself is interdisciplinary. It has some common concepts and theories with such areas, as law, sociology, economy, psychology, mathematics, system theory and cybernetics 
(Bielski, 1996); some authors point also computer science, biology and ecology (ibidem).

The modern organisation is based on processes, which can be found in many different aspects of organisational life. In fact, the recognition of the role of processes in organisations was a key development of the 1990s (Grant, 1998). Product development processes, order fulfilment processes and customer relations processes can be the examples. In other view of the corporation there are: the entrepreneurial process, the competence-building process and the renewal process (ibidem).

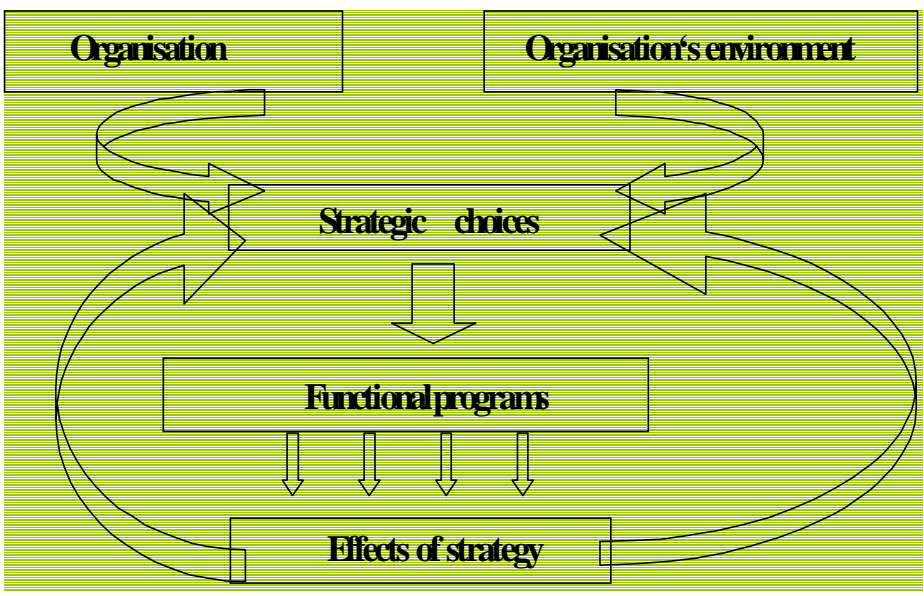

Fig. 1

The process view of organisation had a great impact on the development of knowledge management as a process. Therefore it seems purposeful to stop for a while and have a look on basic processes and cycles that can be distinguished in management science and other areas linked with it, as marketing theory, decision theory etc.

It can be easily noticed, that the concepts which had the biggest impact on knowledge management theory were the following ones:

- decision making process theory

- the process of building company's strategy

- the process of strategic marketing

- the concept of iterative decision making processes (Ghertman's model)

- the product lifecycle concept.

Below we present a short survey of these concepts, pointing out the similarities with knowledge management aspects. Nevertheless, as the question of knowledge management seen as a process is the topic of the next section, here we will only suggest the most outstanding similarities, without getting into the details.
The best known process in the theory of organisation is probably Simon's decision making process (Bielski, 1996). Simon distinguished four phases of this process: problem recognition, solution design, solution choice and finally former decisions evaluation. In the knowledge management area, such a process can be identified e.g. in knowledge base design and development: first, one needs to identify the expertise area (problem recognition), then there come proposals for the construction of knowledge base (solution design), one of those is chosen and implemented (solution choice) and finally a knowledge base is evaluated, verified and modified (former decisions evaluation).

Next there comes a process of strategy development (it is not important here whether we talk about marketing strategy, organisation strategy or competition strategy). Again it is an adaptive process, its essence is shown in Figure 1.The same process can be identified in knowledge based systems and knowledge management systems development: first we investigate company needs and the expertise area ("organisation analysis", "environment analysis"), then we have to make choices concerning the construction and development of the system, which results in a programme of building knowledge base system or knowledge management one, next we measure the effects of using knowledge base or knowledge management system (which is a huge topic

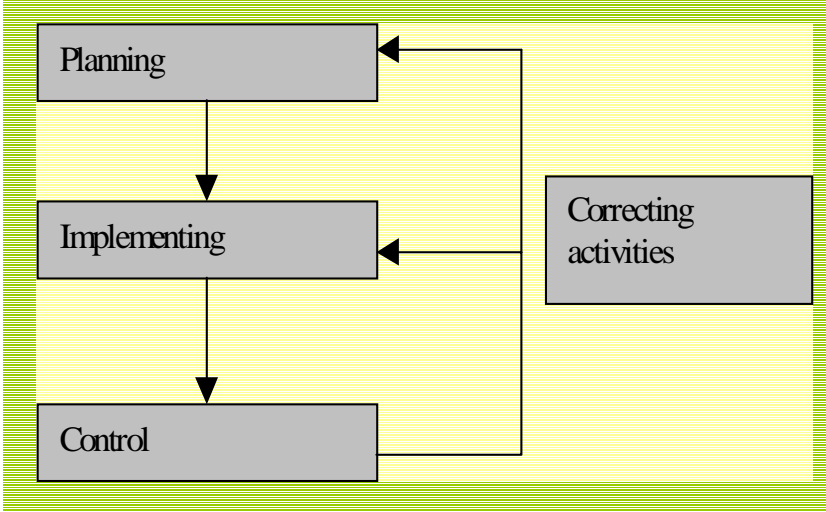

Fig. 2. The strategic marketing process.

itself) and make necessary adjustments. The strategic marketing process (Przybyłowski et al., 1997) is in its nucleus the same as the classical management process (Stoner and Wankel, 1986), as it consists of the following steps (Fig. 2):

Generally speaking, these steps involve (Przybyłowski et al., 1997):

1. planning - inside and outside analysis of the company, designing goals, technical plan (how to achieve goals)

2. implementing - collecting resources, the project of organisation, designing timetables 


\section{Validation as Integral Part}

3. control - comparing real and previously planned effects, making use of positive deflections and correcting negative ones.

As in the previous cases, this process (which can be called adaptive) can be easily reflected in the process of knowledge management, which will be discussed in next section.

Ghertman's concept of iterative decision-making model (STRATEGOR, 1997) could also be viewed as one of those concepts which influenced knowledge management theory. In Ghertman's model we have two dimensions: the dimension of process' phases and the dimension of hierarchical levels. Process phases are as follows: the phase of initiative, when the project is born, "pushing" phase - when the project is promoted, and finally verification phase - the project is accepted or rejected. The phases (especially the last two) can be iteratively repeated until the final decision is taken. It can be clearly seen that such a concept resembles a design phase of building a knowledge management system: first, the idea (project) of a system is born, it has to be promoted (the real need of establishing a knowledge management system must be clearly visible) and finally it has to be accepted. The concept of how to implement the knowledge management system in an organisation is therefore born iteratively - it is often changed until it receives full acceptation.

The second dimension in Ghertman's project - hierarchical levels - concerns the fact, that decisions in an organisation are taken on different managerial levels. Typically, the phases of initiative and promotion take place on lower levels, while the verification phase is connected with higher levels in organisation hierarchy. There obviously is no need to explain, that also decisions concerning knowledge management are taken on different managerial levels and therefore reflect Ghertman's model.

Last but not least, there is a product lifecycle concept and the concept of managing this lifecycle (Przybyłowski et al., 1997). These two concepts form an important aspect of management theory, especially in the marketing area. In our opinion some aspects of knowledge management can also be seen in this way. As an example, let's discuss shortly the problem of knowledge base lifecycle. First we will recall the basic concept of product lifecycle. It defines the phases of product's presence on the market: introduction phase, development phase, maturity phase and finally decline phase. The first phase starts when the product is introduced on the market. During this phase the sale volume grows slowly and the profits are small. In knowledge management aspect, this phase can be recognised when a knowledge base system is introduced in organisation: not many people use it, not many are convinced to use it and therefore the profits of introducing a knowledge base system can be hardly visible. The second phase - development, is characterised by a quick growth of sale volume, because new clients try and start to use the product. The same can be observed in knowledge base lifecycle: the first improvements have already been done, and more and more people in organisation become convinced to use the system. People learn how and in what situations to use the knowledge base system and the profits become more and more clearly visible. In the maturity phase of product lifecycle, the growth of sale volume becomes to reduce, because not many new clients appear on the market. Analogically, in the maturity phase of the knowledge base system, the number of users is stable and so are the tasks of the system and the profits from using it. Finally, the decline phase of product lifecycle starts when the sale volume and the profits start to decrease. It is often due to changes in organisation's environment. It is therefore easy to notice, that because of these changes new tasks arise: new tasks for organisation and consequently for the knowledge base system. Therefore the effectiveness of the system decreases and this is the decline phase in system's lifecycle.

In the short survey presented above we intended to point out analogies between management theory as a whole and the knowledge management theory. In our opinion it is noticeable that the main concept, which had a great impact on knowledge management theory, is the concept of a process. We stressed the most representative trends in the management theory. In the next part of the article we discuss in detail the view of knowledge management as a process.

\section{Knowledge management as a process}

Observing new concepts in information technology, we pay attention to its impact on more effective supporting human and organisational knowledge. Knowledge management $(\mathrm{KM})$ is one of such promising and intriguing concepts. Many authors announce the coming era as knowledgebased century, stressing transformation of information economy onto knowledge economy (see: Van der Spek and Spijkervet, 1997 for example). On the other hand, there are very sceptical opinions that knowledge, as an esoteric category by nature, cannot be managed. Nevertheless, the knowledge management is an idea not only as a topic of many conferences and publications but also there are organisations taking money from this area.

Undoubtedly, like any management task, KM has to be defined its object and goals. Shortly, knowledge, as an ob- 
ject of management, can be understood as the ability to interpret contextual information, to solve problems or to adapt the specific behaviour in the changing conditions. In the business area, knowledge covers organisational structures, its procedures, ways of reaction and the like. It consists of more global elements (including environmental components, noted earlier) used in the entire company as well as parts belonged to individuals. Large pieces of knowledge can be codified using some formalism, in order to draw conclusions from the defined presumptions. These forms of knowledge, closer to information technology and artificial intelligence, are defined as knowledge-bases.

The goals of management, in the case of knowledge, are defined in different ways, comparing to "classical" settings, and (needless to say) are rooted in the disciplines mentioned previously. Usually we stress the necessity of developing and maintaining the good structures of knowledge. Then, knowledge, as a common value, is acquired and shared using efficient methods. Moreover, such knowledge should be controlled in some way. Therefore KM is oriented towards effective techniques of knowledge processing. In other words, knowledge management process represents specific functions integrating socio-cultural as well as technology aspects.

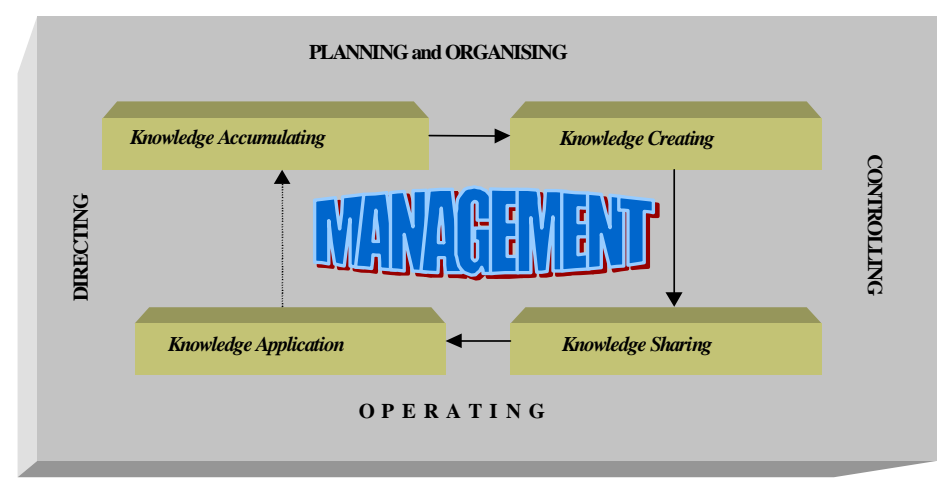

Fig. 3. General structure of knowledge management process.

Adapted from: (Mercier-Laurent, Jakubczyc and Owoc, 1999).

In Figure 3 we demonstrate general structure of knowledge management treating this as an integral process. Management covers "typical" functions: planning and organising, directing and controlling performed in order to achieve defined goals of an organisation. The marked functions are interrelated, therefore performing them, we need information or better - we use specific knowledge. In turn, particular knowledge to be useful has to be properly managed.

From technological point of view, knowledge management can be considered and limited to knowledge processing. Therefore, it covers the following specialised tasks (compare: Jakubczyc and Owoc, 1998), supported with artificial intelligence methods:
- Knowledge accumulating: known as knowledge acquisition, data mining and machine learning - can be automated for extracting knowledge from relevant documents or simply - database files.

- Knowledge creating - knowledge modelling, knowledge representation (in fact, all activities useful in a development process) are phases arising from methods elaborated in "knowledge engineering environments".

- Knowledge sharing - modern technologies (including intelligent browsers) offer almost unlimited access to knowledge resources from any place. For example: a well conceived e-commerce application contains knowledge on products and services, is able to explain how to use products in given contexts, how to connect several devices together, etc.

- Knowledge application - completing the whole process with practical using knowledge-bases in specific environment. In other words, some patterns how to use knowledge to solve different problems are proposed and implemented.

All the marked tasks can be identified with classical managerial functions (planning and organising, controlling and directing or operating) in some way. For example: organising activities consist in developing new forms of knowledge and the same the task knowledge creating is performed. Knowledge accumulating acquires defined goals thus we fulfil "conceptual" functions of management: planning and directing. Effectiveness means controlling managed resources therefore all activities aimed on verification and correction of knowledge are used.

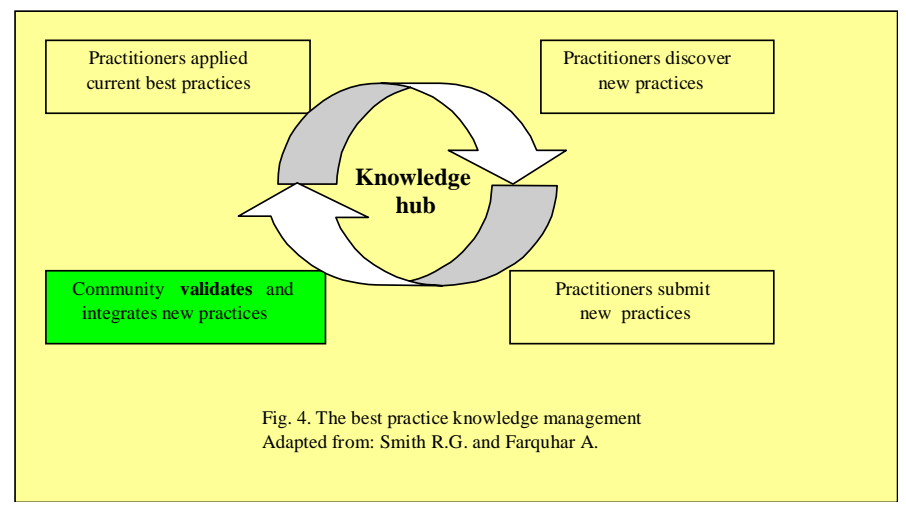

The theoretical and practical background of knowledge processing is formed by artificial intelligence methods. It seems to be obvious, from this short overview of supporting knowledge management by modern technology, not the whole process is "covered" with artificial intelligence means yet. The real need of developing very efficient and integrated tools dedicated to KM functions should stimulate of artificial intelligence techniques and tools. This common area of knowledge management practitioners and 


\section{Validation as Integral Part}

artificial intelligence community arises from sharing goals (see: Smith and Farquhar, 2000).

The contents of knowledge tends to be differentiate. In fact, the following kinds of knowledge are regarded: know-how, know-why and know-what. These particular sorts are concerned with some scientific approaches (state, process and purpose theories, besides of the mentioned in the second section) and learning processes (learning by-doing, importing new theory and "bottom up" or "top down" theories, respectively), see (Sanchez, 1997). In reality more sorts of knowledge can be identifies make process more complicated and difficult to controlling and directing.

\section{Techniques of knowledge validation in the knowledge management context}

Naturally, all the "blocks" of KM have impact on the defined functions of organisational management, especially when operating conditions change. Dynamics of knowledge consists in continuous changes of knowledge structures (see Owoc, 1999). Any of typical knowledge processing modes: insert new parts, deletion of out of date elements or updating its contents means validation of knowledge itself. Figure 4 shows improvement of knowledge centre (called hub) by practice. Therefore, some of methods useful in knowledge-bases validation could be applied in such environment. In our opinion, knowledge validation procedures are very important in the whole management process, however importance and methods of particular tasks are different for the specific knowledge management activities. The critical step is validation and integration of new practices e.g. gathered knowledge.

Despite of the still not totally, concluded discussions on knowledge validation interpretations, there is a commonly accepted opinion of its importance in the whole life cycle of knowledge-based systems including other forms of knowledge. Among the software community, validation is interpreted as "building the right product", verification as "building the product right". After (Laurent, 1992) we assume the validation process can be considered as some determined composition of two kinds of tasks:

- activities that intend to reach the structural correctness of the KB (verification),

- activities that intend to demonstrate the $\mathrm{KB}$ ability to reach correct conclusions (evaluation).

We test knowledge completeness and consistency (verification) or we try to estimate its adequacy and reliability (evaluation). On the other hand, validation refers to differ- ent components of a knowledge-based system. We can validate a knowledge base, inference engine, an user interface etc. In the validation process, two sorts of activities mentioned - verification and evaluation - are complementary and therefore different methods to reach their goals are applied. Figure 5 depicts some details of a knowledge validation infrastructure. There are a lot of approaches defined for validation of a knowledge base, but one can be applied in more global meaning.

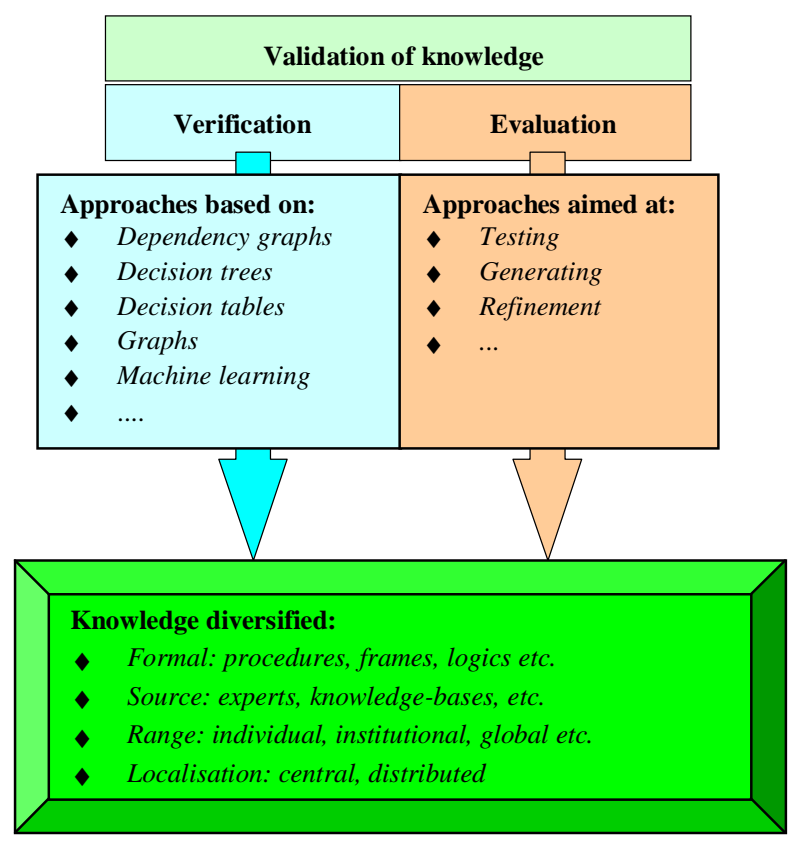

Fig. 5. Validation techniques applied for diversified knowledge Source: own elaboration

All the mentioned techniques from the both sides (verification and validation) can be applied for different knowledge bases expressed in any form. Knowledge derived from different sources can be verified as well as evaluated using the itemised techniques. The other two criteria of knowledge differentiation (range or localisation) confirm usability of the particular techniques. Some research is done in these respects (see Rousset, 1997)

Concluding, we may apply any of the mentioned KV procedure to all activities of knowledge management process, at least from theoretical point of view. However, some of them can play crucial positions in particular circumstances, while others may be used in very limited scopes. For example: evaluation of knowledge adequacy is critical during the first two activities of KM: accumulation and creation. Verification of knowledge completeness and particularly consistency play secondary roles. In turn, the last two criteria (knowledge completeness and consistency) are very important for the second activity - creating. Evaluation of 
knowledge reliability has to be performed in cases of the last two steps: knowledge sharing and application. The other procedures and criteria can be used as supporting tools. Some analogies can be detected considering management in wider perspective. Controlling can be a good example to illustrate of applying very specific methods of knowledge validation. Comparing, being one of the essential tasks of controlling, is strictly tied in with evaluation. In the similar manner, we may apply certain management functions to improve actual knowledge. For example: directing as method of eliminating knowledge inadequacy allows to develop knowledge in a very clear manner.

Summing up, knowledge validation used basically to verifying and evaluation knowledge bases can be apply in the whole knowledge management process. Dealing with knowledge intelligently (see: Van der Spek and Spijkervet, 1997) we have to treat KM as continuous learning process, where validation techniques support all phases of knowledge processing nevertheless of knowledge form, source, range or localisation.

\section{Conclusions}

We have presented some essential notes to knowledge management and validation interrelationships. Knowledge management arising from different theories, became challenge for interdisciplinary research. For sure KM is able to inherit most some very useful techniques applied in different circumstances. Knowledge validation techniques are a good example of such approaches. More formal setting used for validation of knowledge bases seems to be advantage for knowledge not formal expressed. Especially in more detailed framework for knowledge management the mentioned knowledge validation techniques are promising. This is also worth to stress actuality of supporting knowledge management in more intelligent and automatic ways. Based on this, we plan to elaborate a concept of knowledge universal "validator" consisting of set of techniques that can verify and evaluate knowledge existing in many forms.

\section{References}

Bielski M. (1996). Organizacje: istota, struktury, procesy. Wydawnictwo Uniwersytetu Łódzkiego, Łódź.

Grant R. M. (1998). Contemporary Strategy Analysis: Concepts, Techniques, Applications. Blackwell Publishers.

Jakubczyc J. A., Owoc M. L. (1998). Knowledge Management and Artificial Intelligence. Argumenta Oeconomica No. 1(6) Wrocław.

Laurent J.-P. (1992). Proposals for Valid Terminology in KBS Validation. 10th European Conf. on AI, John Wiley \& Sons, Ltd.
Mercier-Laurent E., Jakubczyc J. A,Owoc M. L (1999). What is Knowledge Management? Proc. of the International Conference "Knowledge Acquisition in Databases", Rzeczka, 1999. Research Papers of Wroclaw University of Economics no. 815.

Obłój K. (1998). Strategia organizacji. W poszukiwaniu trwałej przewagi konkurencyjnej. PWE, Warszawa.

Owoc M.L. (1999). On Dynamical Aspects of Knowledge Validation. Proc. of the International Seminar in Krzyżowa. AE Wrocław Research Paper (to appear).

Przybyłowski K., Hartley S. W., Kerin R. A., Rudelius W. (1997). Marketing. Fifth Edition. Richard D. Irwin.

Rousset M.-C. (1997). Verifying the World Web: a Position Statement [in:] Proc. of the $4^{\text {th }}$ European Symposium on the Validation and Verification of Knowledge Based Systems, EUROVAV-97, Leuven (Belgium) Vanthienen J. and van Harmelen F. (eds.)

Sanches R. (1997). Managing Articulated Knowledge in Competencebased Competition [in:] Sanchez R., Heene A. (eds.), Strategic learning and knowledge management, John Wiley \& Sons Ltd, Chichester.

Smith R.G. and Farquhar A. (2000). The Road Ahead for Knowledge Management. An AI Perspective. AI Magazine, Winter 2000.

STRATEGOR (1997). Politique générale de l'entreprise: Stratégie, structure, décision, identité. Dunod, Paris.

Stoner J. A. F., Wankel Ch. (1986). Management. Third Edition. Prentice Hall, Inc., Englewood Cliffs, New Jersey.

Van der Spek R., Spijkervet (1997). Knowledge Management: Dealing Intelligently with Knowledge. [in:] Liebowitz J.L., and Wilcox L.C. (eds.), Knowledge management and its integrative elements. CRC Press LLC, Boca Raton.

\section{Biographies}

Maria A. Mach is a faculty member of the Wrocław University of Economics. Her research interests include knowledge management, artificial intelligence systems in marketing and banking, temporal representation and temporal intelligent systems. She authored and co-authored 15 articles concerning the above mentioned and other areas.

Mieczysław L. Owoc is a Management and Computer Science Faculty member of the Wrockaw University of Economics, where he teaches knowledge- and databasebased courses. Dr Owoc is the author of over 20 papers referring to knowledge validation \& verification and knowledge management topics. 